\title{
OS INSTURMENTOS IMPLICITOS EM UMA CULTURA DE PROJETO PARA A CONSTRUÇÃO DE UM EVENTO: O CASO DO CONGRESSO INTERNACIONAL DE NEGÓCIOS DE MODA
}

\author{
Luciana Bulcão \\ UNISINOS \\ lubulcao@gmail.com \\ Rui Roda \\ UNISINOS \\ rui.roda@me.com
}

Resumo: Este artigo tem como objetivo identificar de que forma a utilização dos instrumentos de metodologias do design se relacionam com a projetação, desenvolvimento e realização de um congresso de moda. Com objetivo de expor de forma mais clara tal relação, se tomará como estudo de caso, o CINM $^{1}$ 2015, realizado na cidade do Porto em Portugal, criado e organizado pelo IBModa².

Palavras-Chave: Instrumentos de Design1. Congresso 2. Negócio de moda3.

\begin{abstract}
The paper aims to identify how the use of design methodologies instruments relate to project, development and realization of a fashion event. As a way to expose more clearly this relationship, it assumes a case study, the 3rd edition of IBC 2015, held in the city of Porto in Portugal, created and organized by IBModa.
\end{abstract}

Keywords: Instrument Design 1. Congress 2. Fashion Business 3.

\footnotetext{
${ }^{1}$ Congresso Internacional de Negócios de Moda- CINM 2015.

${ }^{2}$ Instituto Brasileiro de Moda.
} 


\section{INTRODUÇÃO}

A moda é um fenômeno que, como poucos, é capaz de entrelaçar de forma tão indissolúvel as esferas do econômico, do social, do cultural, do organizacional, do tecnológico e do estético. Ela é, portanto, filha dileta do capitalismo, do qual extrai sua condição de possibilidade (CASTILHO; VILLAÇA, 2006). Assim, o sistema da moda contemporânea organiza-se na sociedade através da premissa da constante renovação, devido ao seu caráter efêmero. Nesse arranjo, inserem-se diferentes tipos de eventos de moda que necessitam acompanhar as mudanças impostas por tal sistema, ao mesmo tempo que necessitam ir de encontro às expectativas do público consumidor.

Contudo, os eventos de moda em geral, carecem de uma constante atualização para que possam disponibilizar novos formatos mais atrativos aos participantes, evitando assim, o desinteresse do público-alvo. Vale considerar que estes eventos estão inseridos em meio ao universo da moda, que se aplica em um campo efêmero e inconstante, onde a oferta de novidades torna-se uma premissa fundamental para a condução da força motriz do setor (MOREIRA, 2010). Sendo assim, estão inseridos neste contexto, os congressos acadêmicos e ou de negócios de moda, onde participam deste ambiente, as universidades e empresas de setor a fim de discutir temáticas atuais do panorama da moda, com o intuito de gerar novos conhecimentos, bem como oportunidades de negócios para no setor.

Para que tal reformulação aconteça se faz necessário um estudo mercadológico do ambiente a ser explorado, alinhado com as necessidades do público-alvo, investimento econômico, além de apoios financeiro e institucional das empresas e universidades. Neste contexto, a principal problemática na construção e desenvolvimento de um congresso orientado ao setor da moda, é encontrada diante das divergências mercadológicas entre o meio empresarial e o meio acadêmico. A situação se agrava no momento em que o evento aborda temas de cunho acadêmico e mercadológico em diferentes momentos. Assim, torna-se mais dificil definir as temáticas a serem abordadas durante o evento, com a preocupação de agradar públicos distintos, bem como a importância e visibilidade que cada palestrante terá durante o mesmo. Sendo assim, algumas são as dificuldades encontradas ao se projetar um congresso orientado a este setor.

Perante tais dificuldades, o artigo tem como objetivo relacionar o uso de instrumentos de metodologias de design assim como os processos de projetação que alcançam uma relação direta na execução de um evento de moda. Dessa forma, pretende-se contribuir com maior atenção para com os congressos de negócios de moda, que por muitas vezes não são levados em consideração por falta de apelo comercial e conceitual em função da escolha e mal definição das empresas presentes. Com o intuito de constituir uma relação entre a utilização dos instrumentos de design com o desenvolvimento de um congresso de moda, será realizado uma análise do caso CINM 2015, que aconteceu na cidade do Porto, em setembro do mesmo ano.

É importante ressaltar que, e sempre que possível, serão estabelecidas as relações com os instrumentos de design utilizados no processo de construção do congresso, bem como a sugestão de alguns instrumentos que não foram utilizados, porém considerados de suma importância para o melhor desempenho do evento. 


\section{METODOLOGIA E INSTRUMENTOS DE DESIGN}

De acordo com Verganti (2008), uma das razões pelas quais a investigação do design é um desafio diz respeito à fluidez implícita na própria noção de design. Em inglês, a palavra design funciona como substantivo e também como verbo circunstância que caracteriza muito bem o espírito da língua inglesa. Como substantivo significa, entre outras coisas, propósito, plano, intenção, meta, esquema maligno, conspiração, forma, estrutura básica, e todos esses e outros significados estão relacionados à 'astúcia' e à 'fraude'. "Na situação de verbo - to design - esta acção significa, entre outras coisas, 'tramar algo', 'simular', 'projetar', 'esquematizar', 'configurar', 'proceder de modo estratégico'” (Flusser, 2007).

Num sentido mais amplo Krippendorf (1989), remete design como algo que transporta um significa de construir algo, distingui-lo através de um signo, dar-lhe um significado, designar as suas relações com as outras coisas, os proprietários, os utentes ou os deuses. Em base de tal significado originário, pode-se dizer: design é construir o sentido (das coisas) para a gestão organizacional. Neste contexto, segundo Stoner e Freeman (1985), o design é uma atividade crucial no processo de inovação, onde as ideias são geradas no domínio da criatividade e acopladas entre possibilidades técnicas, demandas e oportunidades de mercado. Além disto, é uma atividade articuladora e multidisciplinar que integra planos estratégicos e operacionais de acordo com a visão e missão da empresa, desenvolvendo produtos de acordo com as tendências, prazos e custos. Em uma definição mais sintética, entende-se que o design não reside, apenas nos produtos acabados, mas no ato de fazê-los, bem como seu foco não se concentra no resultado, mas sim, no processo (BRANZI in MORAES, 2006).

Para tanto, a fim de ampliar a problematização dos termos discutidos no presente estudo, faz-se necessário retomar alguns conceitos relacionados com a metodologia de design e modelos que a representam. Os modelos de design têm como intuito representar a estrutura de pensar a ação e, consequentemente projetar. Estes formatos possibilitam refletir sobre o método e as técnicas empregadas no processo que são utilizadas a fim de auxiliar no ato projetual, oferecendo-se, com isso, caminhos e possíveis ferramentas para resolver problemas (ROOZENBURG, 1996).

Dessa forma, a metodologia projetual de design reúne diferentes instrumentos que ajudam e colaboram no desenvolvimento de um bem de consumo com intuito de direcionar e indicar possibilidades para determinado problema. A caracterização de cada projeto, é definida pelo uso específico de determinados meios, da mesma forma que um mesmo projeto pode ser desenvolvido a partir de ferramentas diferenciadas (MOREIRA, 2010). Com a proposta de relacionar ferramentas de design com eventos de moda, serão abordados alguns instrumentos que se relacionam com 0 desenvolvimento do projeto de um congresso de moda.

A partir do desenvolvimento do congresso de moda CINM 2015, pode-se perceber, que os instrumentos de brainstorm, mapas conceituais e moodboard foram de extrema importância para a realização de um projeto. Porém, foi possível identificar a partir da pouca adesão do público-alvo ao evento, e da análise de outros resultados considerados importantes para o sucesso do mesmo, a falta que alguns instrumentos oriundos da metodologia do design fizeram ao não serem utilizados. Assim, considerase oportuno uma atenção maior a tais instrumentos. São eles, personas e projeção de cenários. Nesse sentido, para melhor entendimento do estudo que se propõe, será 
apresentado a seguir uma reflexão sobre uma experiência dedicada à edição 2015 do CINM, assinalando a utilização de algumas ferramentas projetuais, como brainstorm, mapa conceitual, mood board. E a sugestão da apropriação de ferramentas projetuais de personas e cenários.

\section{A EXPERIÊNCIA CINM 2015}

Em final de setembro, início de outubro de 2015 realizou-se a produção do CINM - Congresso Internacional de Negócios de Moda, evento de moda que é organizado pelo IBModa com intuito de aproximar mercado organizacional e mercado acadêmico do design e de moda. A partir desta interação, o evento teve como objetivo promover discussões pertinentes e esclarecedoras sobre o mercado do Design e da Gestão da Moda a fim de entender o que acontece hoje e antever o que virá, para projetar oportunidades de negócios e traçar conexões com setores que complementam a indústria da moda.

Através desta experiência, destina-se fazer um estudo de caso, que foi o resultado prático de um estudo teórico ao qual se utilizou de metodologias do design para tornar sua realização viável.

\subsection{Brainstorm:}

Esta ferramenta procurou dar vazão a criatividade através da geração de resultados satisfatórios via um processo coletivo, livre e sem censura. Do inglês "tempestade cerebral", vem da junção das palavras "brain", que significa cérebro, e "storm", que significa tempestade. É também conhecida como tempestade de ideias. Osborn, (1952).

No processo do brainstorming incentivou-se o fluxo de ideias espontâneas e naturais, mas também a flexibilidade e a originalidade do pensamento. $O$ seu princípio base considera que "quanto mais ideias, melhor. " Inicialmente não é feito nenhum tipo de restrição, ou seja, ideias de todos os tipos surgem e são anotadas, para posteriormente elencar e filtrar. As conversas, discussões ou debates são gravados ou anotados para que as ideias sejam registradas. Geralmente as idéias iniciais são as mais óbvias, as mais imaginativas e fantasiosas e costumam aparecer na parte final de uma sessão. (KUMAR, 2013).

Acredita-se que este procedimento estimule os participantes da atividade, agregando, desta forma, interesse um ao outro. A premissa baseia-se na ideia de que não existe o coletivo sem haver o individual. A combinação do individual no grupo, faz com que esta ferramenta possibilite alcançar definições inesperadas se imaginadas individualmente. Existem alguns tipos de brainstorm, entre eles, o estruturado e o não estruturado. A atividade estruturada realiza-se de maneira organizada onde os integrantes atribuem seus pensamentos e associações sobre o projeto de forma sequencial. Cada integrante deve expressar algum termo sobre o assunto, respeitando a sequência dos indivíduos. Neste caso, não convém que um integrante dirija seus pensamentos e percepções ao grupo em momentos distintos da sequência programada. Intitulado como não estruturado, este tipo de brainstorm não possui sequência, possibilitando aos integrantes o intercâmbio dos pensamentos concomitantemente e sem ordenação de expressão de suas percepções. 
A partir das pesquisas de mercado realizada pelo setor de marketing da empresa IBModa' desenvolveu-se um brainstorm não estruturado com três integrantes, com intuito de gerar ideias a partir da temática proposta: "Design, Negócios e Moda: A moda deixa de ser moda e vira negócio". A partir da ideia principal de como a moda deixa de ser moda e torna-se um negócio derivaram-se diversas associações diretas e indiretas com o tema. Algumas palavras relevantes para a temática abordada encontradas foram: Negócios - moda - design - mercadoorganizacional- universidades - trends - comportamento - consumidor - criatividadecenário - Portugal - porto - cidade - portuária - fotografia - viagem- experiência oportunidade - arte - cinema - produção - marketing - merchandising - visual - ensaio - etnografia urbana - exposição - indústria criativa - espetáculo - ecossistemas criativos - cidade criativa - inovação.

\subsection{Mapas conceituais:}

Após o brainstorm, buscou-se o intercâmbio das ideias através do desenvolvimento dos mapas conceituais - representações gráficas semelhantes a diagramas, que indicam relações entre conceitos ligados por palavras, construídas de tal forma que as ligações entre elas sejam evidentes (MOREIRA, 1997). O desenvolvimento de mapas conceituais permite o raciocínio por analogias que se caracteriza por um processo de "identificação, mapeamento e transferência de conhecimentos entre um problema (elemento alvo) e situações familiares paradigmáticas e conhecidas (CASAKIN, 2008). Desta forma, os termos, ideias e expressões oriundas do brainstorm podem ser reunidos por semelhanças e afinidades através de grupos

A partir do brainstorm do caso CINM 2015 desenvolveram-se mapas conceituais a fim de procurar estabelecer ligações entre as palavras obtidas e os estilos das empresas e universidades participantes do congresso, conforme ilustrado na figura 01: Reunião de conceitos oriundos da organização dos mapas conceituais

\begin{tabular}{|c|c|c|c|}
\hline \multicolumn{3}{|c|}{ A MODA DEIXA DE SER MODA E VIRA NEGÓCIO EM 3 EIXOS } \\
\hline \multirow{4}{*}{ Palavras-Chave } & Negócios & $\begin{array}{c}\text { Mercado } \\
\text { Organizacional }\end{array}$ & Inovação \\
& Moda & Design & Universidades \\
& Trends & Comportamento & Consumidor \\
& Fotografia & Viagem & Oportunidades \\
& Portugal & Cidade portuária & Porto \\
& Marketing & Visual Merchandising & Produção \\
& Etnografia Urbana & Cidade Criativa & Ensaio \\
& Industria Criativa & Ecossistemas Criativos & Espetáculo
\end{tabular}

A metodologia utilizada destacou-se em relação ao fato de que cada empresa / instituição acadêmica participante do evento optou por adotar uma temática específica, de acordo com suas áreas de atuação e linhas de pesquisa, seguindo sempre que possível as tendências do mercado da moda e direcionando seus produtos 
e serviços para seus públicos-alvo. Em função da similaridade de conceitos tangíveis e intangíveis obtidos com o brainstorm, as empresas de design e moda, bem como as universidades foram associadas a conceitos muitos próximos, pois ambas permeiam o mesmo universo lúdico e inovador de ambos os setores. Apenas em algumas palavras foi possível uma maior distinção. Contudo, somente uma única palavra se diferencia ente ambos os contextos. A palavra universidade associa-se ao contexto acadêmico. Desta forma, todas as outras palavras fazem referência a ambos os ambientes simultaneamente.

Assim, a reunião dos conceitos auxiliou na divisão da apresentação em três momentos. Obtendo como premissa maior "A moda deixou de ser moda e virou negócio", propôs-se realizar o evento em três dias com abordagens distintas, contemplando assim o público acadêmico e empresarial em diferentes momentos. É importante ressaltar que o evento como um todo contou com quatro dias, porém o primeiro dia ocupou-se somente com a recepção dos participantes. O segundo dia da programação - GPS: Onde estamos e para onde vamos? Abordou temáticas acadêmico e organizacionais, com a proposta: "Oportunidades de inspiração na cultura" - Como a cultura pode ser incorporada em produtos e marcas? O terceiro dia também contou com assuntos de cunho acadêmico organizacional, com a temática "Formas e Volumes"- Design, arquitetura, arte, moda, personalidade, individual, orgânico, home made. Como tudo isso se conjuga? E finalmente o $4^{\circ}$ dia abordou uma temática de viés organizacional com a proposta: FARMÁCIA - Remédios para você, seu negócio, sua empresa: Gestão de Negócios, Gestão de Marcas, Criação de Identidades.

\subsection{Mood Board:}

Segundo Fischer e Scaletsky (2009), o mood board se apresenta com um duplo papel: de ser um meio de criação para novas ideias e de ser um instrumento de diálogo entre os diversos atores envolvidos no projeto. O mood board é uma ferramenta essencialmente visual que vem sendo utilizada pelo Design Estratégico devido à sua forte contribuição para geração de insights. Dessa forma, tal ferramenta vem sendo constantemente utilizada pelo design estratégico devido à sua habilidade de atuar como um mecanismo facilitador de pensamentos (VIEIRA, 2009).

Considera-se que este instrumento aconteça através de raciocínios por analogia ou metáfora e buscam descobrir o desconhecido através do semelhante ou familiar. Atuando enquanto um processo de transferência de conhecimento entre objetos fontes e objetos alvos, esta ferramenta possibilita que o criador estruture ideias em cima de relações estabelecidas. Logo, a relação de semelhança entre dois universos distintos ocorre com o objetivo de conhecer ou descobrir o desconhecido através do semelhante ou familiar (HEYLIGHEN, 2000). O moodboard apresenta-se sob a forma de um quadro que combina uma série de referências visuais que apoiam a criação de uma atmosfera do projeto, principalmente em suas etapas iniciais

Neste sentido, a construção de moodboards pode assim ser associada a construção de conceitos e atmosferas, e não deve ser visto apenas como um instrumento de colagens de imagens isoladas. Moodboards criam vínculos entre as imagens (e outros objetos nele contidos) construindo assim novos significados. A partir do desenvolvimento de três possíveis eixos do "Negócios de Moda" realizou-se uma busca de imagens a partir de recursos da web, através de diferentes sites de moda, design e negócios relevantes para o setor da moda. A figura 03 é constituída do quadro 
resultante da pesquisa imagética do eixo GPS: Onde estamos e para onde vamos? Abordou temáticas acadêmica e organizacionais, com a proposta: “Oportunidades de inspiração na cultura" - Como a cultura pode ser incorporada em produtos e marcas?

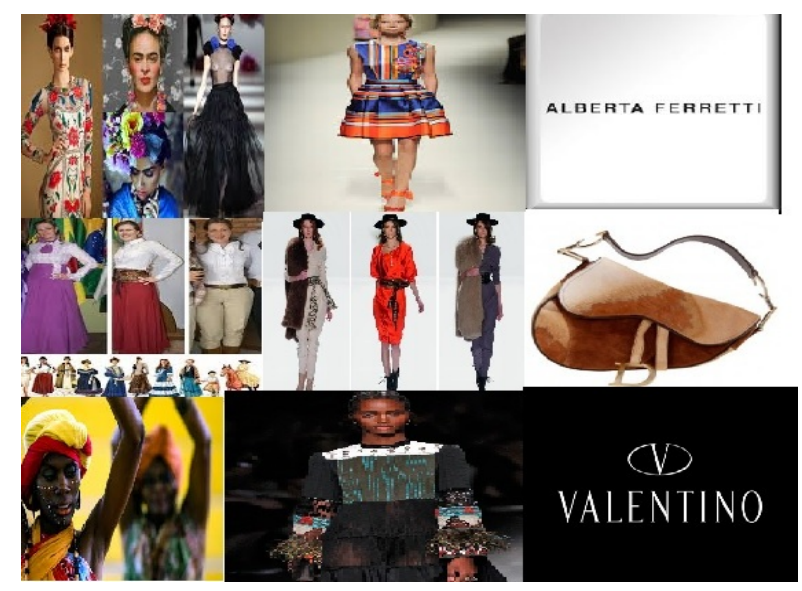

Figura 1: Resumo de imagens relacionadas com o eixo Oportunidades de inspiração na cultura" Como a cultura pode ser incorporada em produtos e marcas Fonte: Ibmoda

A pesquisa de imagens relacionada com o tema "Formas e Volumes"- obteve como princípios chaves alguns elementos: Design, arquitetura, arte, moda, personalidade, individual, orgânico, home made, onde a proposta era como conjugar todos estes elementos ao mesmo tempo.

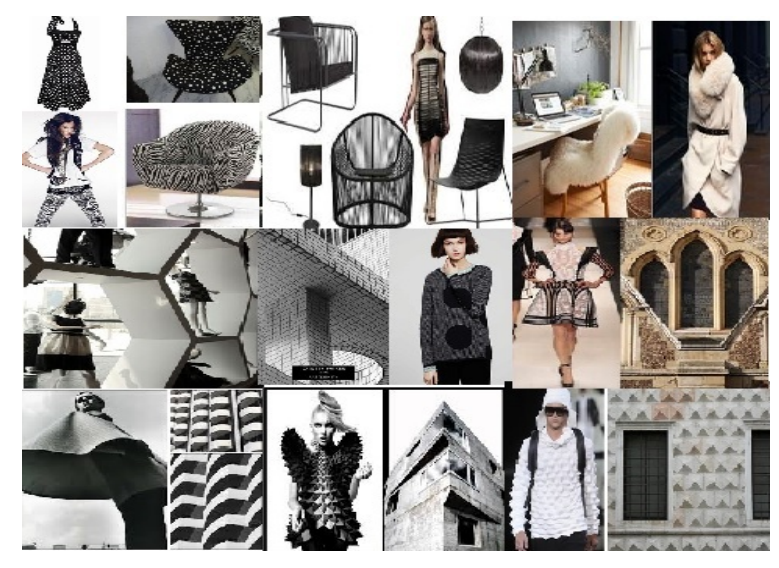

Figura 2: "Formas e Volumes"- Design, arquitetura, arte, moda, personalidade, individual, orgânico, home made, Como tudo isso se conjuga?

Fonte: Ibmoda

A pesquisa imagética referente ao grupo "Farmácia: Remédio para o seu negócio" relacionou-se com ambientes de negócios de moda e gestão de marcas, através de imagens de feiras, congressos e palestras de moda, bem como de empresários atuando no setor. 


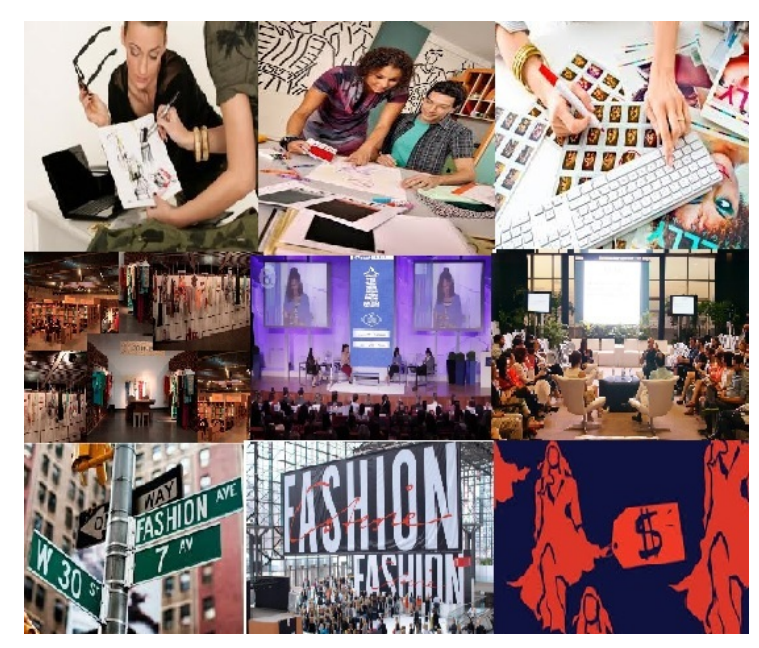

Figura 3: FARMÁCIA - Remédios para você, seu negócio, sua empresa: Gestão de Negócios, Gestão de Marcas, Criação de Identidades

Fonte: Ibmoda

\section{UM OLHAR SOBRE A EXPERIÊNCIA CINM 2015}

Através da análise de caso do CINM - pode-se perceber que as ferramentas de design utilizadas para o desenvolvimento e construção do projeto foram ao que elas se propunham, não só satisfatórias, bem como indispensáveis para o bom andamento do projeto. Entretanto, os resultados mercadológicos obtidos na $3^{\circ}$ edição do $\mathrm{CINM}$ não foram suficientes e satisfatórios ao que o evento se propunha inicialmente. A situação se agravou no momento em que o número de inscritos ficou muito abaixo do previsto.

A partir dos resultados não satisfatórios obtidos, e com o intuito de pensar a projetação da próxima edição do evento, será proposto a inserção de duas ferramentas do design, que após análise e estudo minucioso das diferentes fazes de projetação do evento, foram consideradas necessárias a fim de complementar as ferramentas utilizadas anteriormente, e neste caso adotadas especificamente para proporcionar uma maior assertividade do público-alvo, bem como, de que forma encontrá-lo. Diante deste contexto, como proposição de melhorias, serão então sugeridas as ferramentas de "Personas" e Projeção de Cenários.

\subsection{Personas:}

A técnica de Personas foi criada por Cooper, no livro "The Inmates Are Running the Asylum" de 1999. Segundo o autor, persona seria um método de projetar tendo em vista uma pessoa ao invés de tentar satisfazer inúmeras: "para criar um produto que satisfaça uma ampla audiência... você terá muito mais sucesso se o projetar visando satisfazer uma única pessoa" (COOPER apud PRUITT; ADLIN, 1999). Em suma, personas são arquétipos que descrevem vários objetivos e padrões de comportamento observados entre os potenciais usuários e consumidores (GOODWIN, 2009). Nesse sentido, é possível relacionar o uso desta ferramenta no desenvolvimento do CINM, objetivando obter de forma mais precisa o perfil do público-alvo a ser abordado.

Cada persona é baseada em um personagem fictício cujo perfil reúne as características de um grupo social existente. Desta forma, as personas assumem os atributos dos grupos que representam a partir das suas características sociais e 
demográficas, suas necessidades, desejos, hábitos e origens culturais. O aspecto especial de uma descrição de personas é que você não olha para o todo da pessoa, ela é como uma lente que destaca as atitudes relevantes para o processo.

Assim, para um projeto de design, a ferramenta de personas proporciona vantagens no momento que amplia o Mindset, constrói empatia, define direções, inspira ideias e estrutura o conhecimento existente (KUMAR, 2013). Ainda segundo o autor, esta ferramenta também gera Input através dos achados de pesquisas etnográficas, lista de potenciais usuários, lista de atributos destes potenciais usuários e Output através do conjunto de personas baseado em diferentes atributos, que sugere conceitos de exploração, apoio ao processo do problema sob o ponto de vista dos usuários. Ao utilizar a fermenta de personas encontra-se os usuários através de pesquisa quantitativa. Assim é possível distinguir quais as diferenças entre os usuários, construindo hipóteses através da análise de conteúdo, bem como verificar atributos através de pesquisa qualitativa.

A fermenta ainda consiste na procura por padrões, pois ao construir personas deve-se definir situações, validar tais hipóteses, para então criar cenários (em uma dada situação, com um dado objetivo, o que faria esta persona?), para finalmente desenvolver testes de usabilidades, feedback dos usuários (KUMAR, 2013).

\subsection{Construção de cenários:}

Os cenários são concebidos como instrumentos a serem utilizados no processo de criação do design. Segundo Ferreira (2008) eles possibilitam a simulação de múltiplas situações espaço temporais da empresa em conexão com as diversas variáveis do mercado, possibilitando assim prever problemas e desencadear ações corretivas antes que ocorram. Heijden (2004) salienta que a construção de cenários amplia a percepção do mundo exterior para além dos modelos de negócios tradicionais. Esta ferramenta também ajuda nos aspectos de diferenciação e integração da organização que a utiliza. Dessa forma, a utilização da construção de cenários é um passo importante, pois simula o que poderá acontecer à empresa, se desenvolvidas determinadas ações e processos. Essa ação pode evitar fracassos, motivar sucessos e, principalmente, a reinvenção, quando necessário, do próprio plano de negócio (FERREIRA, 2008).

A criação de cenários também permite uma reflexão sobre quais as tendências que estão se constituindo, através da busca de informações e da construção de narrativas onde há conexão entre todas as informações direcionadas ao projeto; possibilita refletir sobre as diferenças e sintetiza-las em um novo modelo. Esta ferramenta contempla a identificação de elementos de inovação, sugerindo direções nas quais a visão da organização pode ser ampliada e conduzindo a uma estratégia original. Quando utilizada através da lógica do Design Estratégico, a construção de cenários estrutura-se em três partes: a Visão, que evidencia um contexto e sugere como ele poderia ser; a Proposta, que consiste na concretização desta Visão; e pôr fim a Motivação, que contempla os objetivos e dá significado à existência deste cenário (MANZINI, 2004). 


\section{CONSIDERAÇÕES FINAIS}

A partir do estudo proposto é possível entender que em suma o projeto de design ocupa-se de um processo não linear e inconstante, porém, suas metodologias apoiam-se em ferramentas e instrumentos que facilitem seu caminho criativo. Tais etapas relevam-se na ideia de que as mesmas podem ser utilizadas em diferentes construções de bens de consumo, seja ele um produto ou um serviço (MOREIRA,2009). O presente estudo objetivou identificar de que forma a utilização dos instrumentos de metodologias do design se relacionam com a projetação, desenvolvimento e realização de um congresso de moda. Assim, no decorrer do desenvolvimento da análise de caso, pode-se mencionar a importância de tais ferramentas para a construção do congresso de moda, num ambiente onde universidades e empresas se fazem presentes, dividindo seus espaços e segmentos em um mesmo espaço.

Perante tal ambiente, onde configuram-se distintos perfis profissionais dentro de um mesmo espaço, faz-se necessários diferentes tipos de temáticas a serem abordadas com intuito de comtemplar a todos. Assim, foi fundamental o desenvolvimento e planejamento de um método com o intuito de organizar as inúmeras variantes que constituíam tal cenário.

Vale destacar que a metodologia aplicada no evento analisado se refere exclusivamente a este projeto e não se estabelece em uma fórmula ou uma estrutura pré-estabelecida para a construção de outros eventos deste porte. Portanto, os critérios de desempenho, bem como as ferramentas utilizadas podem não vir ao encontro de outros casos de congressos de moda, pois as necessidades dos projetos variam conforme as necessidades a eles inseridas. Apesar disto, compreende-se a importância do conhecimento da metodologia de design, bem como os instrumentos que facilitam este processo. A partir deste entendimento, o designer possui um maior conhecimento, que contribui para que ele possa escolher as ferramentas de design mais apropriadas para o desenvolvimento dos problemas que lhes são apresentados, objetivando assim, uma maior assertividade

\section{REFERÊNCIAS}

BRANZI, Andrea in MORAES, Dijon. Análise do design brasileiro: entre mimese e mestiçagem. São Paulo: Edgard Blücher, 2006.

COOPER, R.; PRESS, M. The design agenda: a guide to successful design management. Chichester: Wiley, 1995.

FERREIRA, Aurélio Buarque de Holanda. Minidicionário Aurélio da língua portuguesa; coordenação Marina Baird Ferreira, Margarida dos Anjos; equipe Elza Tavares Ferreira.(et al). 3 eds. Rio de Janeiro: Nova Fronteira, 1993.

FERREIRA, A.R.; STEFANO, N.; JOÃO, D. M.; GODOY, L. P. A gestão de design estratégico para produtos ecologicamente corretos. II Encontro de sustentabilidade do Vale do Itajai, abril 2008.

FISCHER, G.; SCALETSKY, C.; Intuição e Método de design. São Paulo: SIGraDi, 2009. FISCHER, G.; SCALESTSKY, C. C.; AMARAL, L. G. O storyboard como instrumento de projeto: reencontrando as contribuições do audiovisual e da 
publicidade e seus contextos de uso no design. Strategic Design Research Journal, 3(2): 54-68 maio-agosto 2010.

FLUSSER, V. O mundo codificado: por uma filosofia do design e da comunicação. São Paulo: Cosac Naify, 2007.

GOODWIN, K. Designing for the digital age. Indianapolis: Wiley Publishing, 2009.

HEIJDEN, Kees Van Der. Planejamento de cenários: a arte da conversação estratégica. Porto Alegre: Bookman, 2004.

HEYLIGHEN, Ann. In case of architectural design - critique and praise of case - Based Design in architecture. Tese de doutorado. Leuven: Katholieke Universiteit Leuven, $p$. 16- 25, 2000.

KUMAR, V. 101 Design Methods: A Structure Approach for Driving Innovation in Your Organization. 1ed. New Jersey; John Wiley \& Sons, 2013.

KRIPPENDORFF, K. On the essential contexts of artifacts or on the proposition that design is making sense (of things). Design Issues, v, 5, n. 2, 1989.

MACHADO, Regina. Fim da linguagem imutável, início do sex-appeal das jóias. In: CASTILHO, Kathia; VILLAÇA, Nízia (Org.) plugados na moda. São Paulo: Anhembi Morumbi, 2006. Cap. 14, p. 116-125.

MANZINI. Ezio. On Service Design. Copenhagen: Service Design Symposium, 2008. MORAES, Dijon. Limites do design. 2. ed. São Paulo: Studio Nobel, 1999.

MOREIRA, B; SCALETSKY, C.; O uso de instrumentos de design na construção de eventos de moda. São Paulo: "9o Congresso Brasileiro de Pesquisa e Desenvolvimento em Design".2009.

OSBORN, A. F. Your creative power: How to use imagination. New York: Scribners, 1952

ROOZENBURG, N.F.M. EEKELS, J. Product Design, Fundamentals and Methods. Wiley: Chichester, 1996. SCALETSKY, Celso C. Criação de bibliotecas de conceitos a partir de uma Base de Projetos de Arquitetura. SIGraDI 2006, Santiago, Universidad de Chile, 2006. . Pesquisa aplicada / pesquisa acadêmica - o caso Sander. In: Anais do Oitavo Congresso Brasileiro de Pesquisa \& Desenvolvimento em Design, São Paulo: Centro Universitário SENAC, 2008, pg. 1132-1145.

STONER, James A. F.; FREEMAN, R. Edward. Administracão. 5. ed. Rio de Janeiro: Prentice Hall Regents, 1985, 533 p.

VERGANTI, Roberto. Design-Driven Innovation: mudando as regras da competição: a inovação radical do significado de produtos. São Paulo: Canal Certo, 2012a. 